\title{
A Comprehensive Model of Consumers' Perceptions, Attitudes and Behavioral Intention toward Organic Tea: Evidence from an Emerging Economy
}

\author{
Xiangzhi Bu ${ }^{1}\left(\right.$, Hoang Viet Nguyen ${ }^{2}(0)$, Tsung Piao Chou ${ }^{3, *}$ and Chia-Pin Chen ${ }^{3}$ \\ 1 Department of Business Administration, Business School, Shantou University, Shantou 515063, China; \\ xzpu@stu.edu.cn \\ 2 Department of Research Administration, Thuongmai University, Hanoi 100000, Vietnam; nhviet@tmu.edu.vn \\ 3 Department of Business Administration, National Chung Hsing University, Taichung 402, Taiwan; \\ cpchen@dragon.nchu.edu.tw \\ * Correspondence: choutsungpiao@gmail.com
}

Received: 31 July 2020; Accepted: 13 August 2020; Published: 15 August 2020

\begin{abstract}
This study investigates factors that predict consumers' perceptions of healthiness of organic tea. Furthermore, this study also examines the relationship between perceived healthiness and purchase intention with the mediating role of consumers' attitudes toward organic tea. Because China has been the largest producer and the largest market of the global tea market, this study collects sample data from consumers at different tea stores in China. Using structural equation modelling to analyze data, results indicate that product quality, consumer service, in-store experience, store prestige, and store innovativeness are important predictors of consumers' perceptions of healthiness of organic tea. Furthermore, results show that perceived healthiness has a positive influence on purchase intention toward organic tea. Consumers' attitudes toward organic tea also has a positive mediating effect into this relationship.
\end{abstract}

Keywords: perceived healthiness; product quality; consumer service; in-store experience; pricing policy; store prestige; store innovativeness; purchase intention

\section{Introduction}

Tea is known as the world's second most popular beverage after water [1,2]. According to Global Market Report [3], the amount of tea production of the world in 2017 was 5.98 million tons and retail value of tea products was nearly USD 50 billion. Retail sales have remained a high growth rate in the last decades. Furthermore, the largest tea production country is China which exported an amount of USD 1.6 billion in 2017. The total tea consumed in China is more than the combination of all tea consumption of other countries in the world. Tea product is expected to be the largest potential market of beverage in developed and developing countries in the next few years [3].

Organic tea has become the most important types of tea products that receives consumers' great demand in the last few years [1]. According to Global Market Report [3], the global organic tea will reach more than USD 1.3 billion in 2024 . The average growth rate will be approximately $5.8 \%$ during 2019-2024. Several types of organic tea have been sold in the global markets, including black tea, green tea, and others. North America has dominated the global organic tea in the last decades due to a large market demand with great purchasing power of consumers. Asia-Pacific has also accounted for a significant market share in the global organic tea market. It is estimated that Asia-Pacific will be the largest market for organic tea in the next few years [3]. Some of the largest producers and sellers of organic tea in the global market are Unilever, Tata Global Beverages Limited, Stash Tea Company, 
Shangri-la Tea, Yogi Tea, Mighty leaf Tea, Zhongshan Standard Industry Company, Hunan MeeTea Company, and others [2,3].

Regular consumption of tea can provide consumers with different benefits (e.g., anti-diabetic, anti-aging and pro-metabolic) and reduce depression risks [2,4,5]. Notably, organic tea is widely recognized as a safe and healthy product because it is free of chemical residues, fertilizers and pesticides [6,7]. Organic tea is cultivated by unique production systems and techniques that sustain the health of soils, ecosystems and people health [8]. The demand for organic tea has increased rapidly in the last decades. Several reasons attribute to this increase, including enhancement in consumers' income and consumption knowledge, high regulations from government to develop sustainable agriculture, and high standard from certificated institutions [9]. For example, Voluntary Sustainability Standards (VSS) is a global standard that is often used to certify tea and coffee products. More specifically, VSS requires tea producers to comply with high standards that enable climate resilience, prevent soil erosion, and protect consumers' health. In addition, the standard is used to ensure tea products that are produced to meet consumers' demands while maintain the goal of sustainable development.

While numerous studies have investigated the consumption of organic food in general [10-14] and specific categories, such as organic meat $[15,16]$, organic milk $[17,18]$, organic fruits and vegetables $[19$, 20], research on organic tea is still very limited. Several prior studies have primarily focused on the production and plantations of organic tea [21,22]. Other studies also focus on tea culture and marketing of organic tea product $[1,6,8]$. However, little knowledge is known about consumers' perceptions and purchase decisions toward organic tea, despite a large increase in consumer demand for such a healthy beverage. A notable study conducted by Sumi et al. [6] in Bangladesh found several predictors of consumer intention to purchase organic tea, including perceived price, trust, environmental concern and health benefit. However, this study underestimated the impact of store-related factors such as store prestige, store innovative and in-store experience. It also failed to investigate the role of potential mediators in explaining consumer's purchase intention associated with organic tea. Furthermore, it should be also noted that although China is the largest tea production and the largest tea market in the world [3], few studies have determined the antecedents of consumers' perceived healthiness of organic tea and how such a perception influences consumer purchase decision-making. This lack of research provides very limited knowledge for researchers and business managers in tea industry in China market. To fill this gap, this study aims at investigating key factors that predict consumer perceived healthiness of organic tea. Furthermore, this study also determines the relationship between perceived healthiness and purchase intention with the mediating role of attitudes toward organic tea.

This study is expected to offer further insights for researchers and business managers in the tea industry to develop more effective marketing strategies aiming at promoting the consumption of organic tea. Furthermore, given that the present study focuses on consumers and tea stores in China, its findings will enrich the literature relating to purchase behavior and consumption of organic tea in emerging markets, where there are increasing demand for healthy and safety tea products [23-26].

The remaining of this study is organized as follows. The second section discusses literature and develops hypotheses. The third section discusses research method and sample data. The fourth section presents results. The fifth section provides a detailed discussion of both theoretical and managerial implications. The final section presents the research limitations and future research directions.

\section{Literature Review and Hypotheses}

\subsection{The Tea Market in China and Chinese Tea Culture}

China is known as the largest tea market in the world. According to Worldteanews.com, Chinese consumers drink more than 40 percent of the world's tea. China's tea market is estimated about 67 billion RMB. Furthermore, China also produces the largest tea products in the world with more than 2.62 million tons in 2018 ( $44.7 \%$ of the whole world's tea). The tea sales revenue in China reached 
240 billion RMB in 2018 and 284 billion RMB in 2019. Demand for tea products in China is largely increasing in the next few years which creates great opportunity for tea business in China market.

Hinsch [27] stated that Chinese consumers prefer to drink tea. Drinking tea habit is indifferent between men and women and between geographic area in China [10]. Chinese consumers prefer high quality of tea. They often rely on third-party certificate to ensure the tea is organic and sustainably grown [28]. Furthermore, Chinese consumers mainly purchase tea from physical stores such as exclusive stores or large supermarkets [27]. Recently, there is a substantial change in Chinese consumers' preference for tea products that they pay more attention to personal health [22]. Because tea is a health-related product and has become daily necessity, Chinese consumers are strongly aware of health. Thus, organic tea tends to be the first choice in their purchase decision of tea products $[8,28]$.

Drinking tea has been a cultural custom in China for more than four thousand years. It is a daily habit for many Chinese people [28]. Tea is also consumed in formal occasions in China. Tea culture in China is often known as "the art of drinking tea-Chayi" [28]. It is believed that drinking tea not only helps to refresh, prevent disease, and increase health but also represents different meanings between people in social life [28]. For example, tea is a sign of respect of younger people to older people, to show gratitude and celebrate weddings, and to apologize [27]. Furthermore, Chinese tea is often connected with literature, arts philosophy. It also reflects several Chinese cultural values such as Confucianism, Taoism, and Buddhism [29].

\subsection{Prior Studies on Organic Tea and Organic Foods}

Organic foods have been a core research issue in prior literature $[23,26]$. Despite organic tea is a type of organic foods [1,2], studies on antecedents and consequences of organic tea consumption has still been limited in literature. The study of organic foods may provide important theoretical basis for research on organic tea consumption [6]. Prior studies have investigated several factors that determine consumers' attitudes and behavioral intention toward organic foods [4]. For example, Jensen et al. [9] examined several factors that affect consumers' perceptions of organic foods, including food safety, taste of organic foods, animal welfare, and environmental impacts. Chen [10] found that health and environmental concerns are predictors of consumers' purchase intention toward organic foods. Chekima et al. [11] reported that product-specific attitude, willingness to pay, and perceived availability have a significant positive impact on consumers' actual behavior of organic food consumption. Hoffman et al. [12] suggested that factual concernment and perceived concern are the two important factors that determine consumers' intention to purchase organic foods. Several other studies also investigated factors regarding to health and environmental protection as main antecedents of organic food consumption $[13,14,16-18,20,21]$. In sum, these studies have provided rich evidence on the factors that influence consumers' purchase behavior toward organic foods. The findings of these studies have provided implications for this study to investigate factors that influence consumers' perceptions, attitudes, and behavioral intention toward organic tea.

\subsection{Antecedents of Perceived Healthiness of Organic Tea}

\subsubsection{Product Quality}

Product quality is often viewed as a key factor that differentiates organic tea products from traditional tea products [30]. Specifically, consumers evaluate organic tea as high product quality because organic tea contains rich nutrition. It is naturally plant without chemicals and processed without preservatives [31]. Traditionally, Chinese consumers buy tea products with a main focus on their taste, price, and convenience. However, as income increases and consumption knowledge advances, Chinese consumers pay more attention to the safety and health of tea products [32]. In particular, after COVID-19 pandemic occurs, Chinese consumers prefer organic tea and they are willing to purchase organic tea to replace traditional tea products [3]. The reason is that organic tea does not contain synthetic residues, herbicides, and pesticides [6,8]. It is also believed that organic tea is safe for human 
health [22,27]. Thus, consumers often perceive organic tea as healthy products because its quality is better than traditional tea products. The following hypothesis is therefore proposed.

Hypothesis 1 (H1): Product quality is positively related to perceived healthiness of organic tea.

\subsubsection{Customer Service}

Traditionally, Chinese consumers do not rely heavily on customer service to purchase tea products because most of tea products are sold through conventional small stores with little or no service [32]. In the last decades, with the emergence of large stores and exclusive stores and the increase in consumers' purchase power, consumers tend to care more about customer service because they have more choices for their money. As a result, consumers' purchase of organic tea depends largely on customer service [33]. For example, consumers may rely on personnel's knowledge and service quality to decide whether to purchase organic tea. Furthermore, customer service may act as a signal to deliver message about the healthiness of organic tea [3]. For example, if personnel of tea stores are professional with rich knowledge about tea products, they will provide sufficient information and make consumers understand about the safety and healthiness of organic tea. With the assistance of personnel, consumers can distinguish the difference between organic tea and conventional tea. Thus, it is expected that customer service will enhance consumers' perceptions about the healthiness of organic tea. The following hypothesis is therefore formulated.

Hypothesis 2 (H2): Customer service is positively related to perceived healthiness of organic tea.

\subsubsection{In-Store Experience}

The emergence and development of online stores have generated tremendous challenge and threat to traditional physical stores [34]. With several advantages such as lower price, more convenient, and more cost saving, online stores are becoming a replacement of physical stores in providing products and services for consumers. Researchers have suggested that physical stores should focus on creating shopping experience for consumers in order to compete with online stores and satisfy consumers' needs [34,35]. Although young Chinese consumers tend to shop online, most of tea consumers still prefer to purchase tea products at physical stores [36]. For many consumers, shopping is not only purchasing products but also enjoying the pleasant of shopping trips. For example, several consumers come to tea stores to browse products, meet friends, engage in social interaction, and enjoy tea culture "Chayi" [37]. A positive in-store experience may make consumers feel happy and satisfy with the physical stores and tea products. Consequently, they may hold positive perceptions of healthiness of organic tea because they experience shopping trip in the tea store (e.g., consumers may taste and evaluate organic tea at stores when they visit tea stores) [6]. Thus, it is expected that in-store shopping experience helps consumers recognize the healthiness of organic tea as a result of their shopping experience in tea stores. The following hypothesis is therefore proposed.

Hypothesis 3 (H3): In-store experience is positively related to perceived healthiness of organic tea.

\subsubsection{Pricing Policy}

Kotler and Armstrong [35] stated that price may be the most important factor that directly affects consumers' purchase decision. Because price often determines the value of a product, consumers often evaluate the quality of product based on price. Generally, high price is associated with high product quality whereas low price represents low product quality [35]. Organic tea is often plant with special care and complies with the standard of organic farming. The farming of organic tea 
is not allowed using pesticides and fertilizers. Because farming and process of organic tea require special technique and cost more than conventional tea products. Its quality is better, and its price is higher than conventional tea products [36]. Therefore, high price indicates high quality of organic tea because people often believe that organic tea has high content of nutrients and thus are healthier than conventional tea $[22,27,28]$. It is expected that pricing policy will act as a signal to reveal the healthiness of organic tea [16]. That is, low price policy may signal unhealthiness whereas high price policy delivers the message of healthiness of organic tea to consumers $[8,19,30]$. Hence, the following hypothesis is formulated.

Hypothesis 4 (H4): High price policy is positively related to perceived healthiness of organic tea.

\subsubsection{Store Prestige}

Store prestige often plays an essential role in influencing consumers' purchase decisions [37]. Consumers often perceive high prestige as an assurance that represents the stores as reliable and dependable which provide high product quality and excellent service for consumers [38]. Several consumers tend to buy from prestige stores because they obtain higher value for their money as compared with purchasing from other stores [39]. In tea retailing industry in China, store prestige is one of the most important factors that affect consumers' purchase decision. Several traditionally historical tea stores have become a social interaction and main purchasing point of local consumers. Chinese consumers often choose to purchase tea products from these long-historical stores because they believe that these stores provide better tea products than other stores. Similarly, consumers may believe that purchasing organic tea from high prestige stores is more reliable because they obtain high assurance from these stores. Consumers may also believe that prestige stores will provide organic tea that is safer and healthier than that of other stores. Therefore, it is expected that store prestige may influence consumers' perceptions of healthiness of organic tea because consumers believe in product quality that is provided by high reputation stores. The following hypothesis is proposed.

Hypothesis 5 (H5): Store prestige is positively related to perceived healthiness of organic tea.

\subsubsection{Store Innovativeness}

Store innovativeness refers to the innovation in products, services, and physical environment of tea stores [37]. Consumers often enjoy innovation because they have new choice to satisfy their needs. They also obtain new value for their money [40]. Although tea products are low involvement products which require low efforts in decision making and less price than other luxury products, consumers demand more than only tea product itself due to an increase in their purchase power and consumption knowledge [41]. Consumers not only buy tea products but also come to tea stores to enjoy social interaction and experience shopping trip. Store innovativeness implies that tea stores provide different new tea products which increase consumers' choices. Tea stores also provide new services to enhance consumers' satisfaction. An innovation in physical environment of tea stores also excites consumers and increases their shopping experience [42]. Therefore, it is expected that store innovativeness will increase consumers' perceptions of healthiness of organic tea because consumers may hold a perception that organic tea of innovative stores is often better than that of other stores. The following hypothesis is formulated.

Hypothesis (H6): Store prestige is positively related to perceived healthiness of organic tea. 


\subsection{Perceived Healthiness and Purchase Intention toward Organic Tea}

Drink tea has been a traditional culture in China. Tea product is a necessity in Chinese daily life. Chinese people use tea to serve visitors and replace water for drinking, use tea as medicine, and treat tea as a type of health-keeping method-"Chayi" [28]. To obtain the best quality of the abovementioned purposes, selection and purchase of tea products are very important. In recent years, Chinese consumers tend to purchase high quality of tea products because of increases in purchase power and consumption knowledge [43]. Organic tea becomes the first choice of numerous tea consumers because of its widely accepted benefits and values. On one hand, organic tea is known as high-end products that have better quality than other types of tea. Organic tea is safe and healthy because it is grown without pesticides, chemicals, and fertilizers [44]. On the other hand, organic tea has less negative impact on environment as compared with other types of tea, because cultivation and treatment process of organic tea have to comply with strict standard [45]. Therefore, when Chinese consumers perceive the healthiness of organic tea, they will hold a high intention to purchase organic tea because they feel safe and healthy with organic tea. The following hypothesis is developed.

Hypothesis (H7): Perceived healthiness is positively related to purchase intention toward organic tea.

\subsection{The Mediating Role of Attitude toward Organic Tea}

Attitude is defined as "people's evaluation of almost any aspect of the world" (p.163, [46]). Specifically, an attitude is "a lasting, general evaluation of people, objects, advertisements, or issues" (p.285, [47]). An individual's attitude toward a certain object can be explained by the ABC attitude model. This model indicates the interrelationship between affect (A), behavior (B), and cognition (C) in forming an individual's attitude toward an object [48]. In some cases, attitude is formed when people perceive (C), feel (A), and take action (B) toward an object [47]. For example, when a person smells the odor of Starbucks' coffee, he or she may feel and think that Starbucks often provides high quality of coffee. Given this perception and thinking, he or she may take action to purchase coffee from Starbucks.

$\mathrm{ABC}$ attitude model can be used to explain consumers' behavior toward organic tea. In particular, organic tea is safer and healthier than other types of tea products. It is cultivated naturally without pesticides. Therefore, organic tea is good for human wellbeing and also the natural environment. Generally, consumers often prefer organic tea due to its benefits and high quality. When consumers perceive the benefits and healthiness of organic tea, they may positively evaluate organic tea as superior than other tea products. That is, consumers may form positive attitudes and hold positive feelings about organic tea. Consequently, they are likely to purchase organic tea because it creates more value for consumers. Thus, it is expected that consumer perception of healthiness will enhance consumers' positive attitudes which in turn increase consumers' intention to purchase organic tea. The following hypothesis is developed.

Hypothesis 8 (H8): Attitudes positively mediates the relationship between perceived healthiness and purchase intention toward organic tea.

The research model of this study is shown in Figure 1. It is hypothesized that product quality (H1), customer service $(\mathrm{H} 2)$, in-store experience $(\mathrm{H} 3)$, pricing policy $(\mathrm{H} 4)$, store prestige (H5), and store innovativeness (H6) will positively predict consumers' perceptions of healthiness of organic tea. Furthermore, it is inferred that perceived healthiness will positively related to purchase intention toward organic tea (H7). In addition, it is argued that attitudes will positively mediate the relationship between perceived healthiness and purchase intention toward organic tea. 


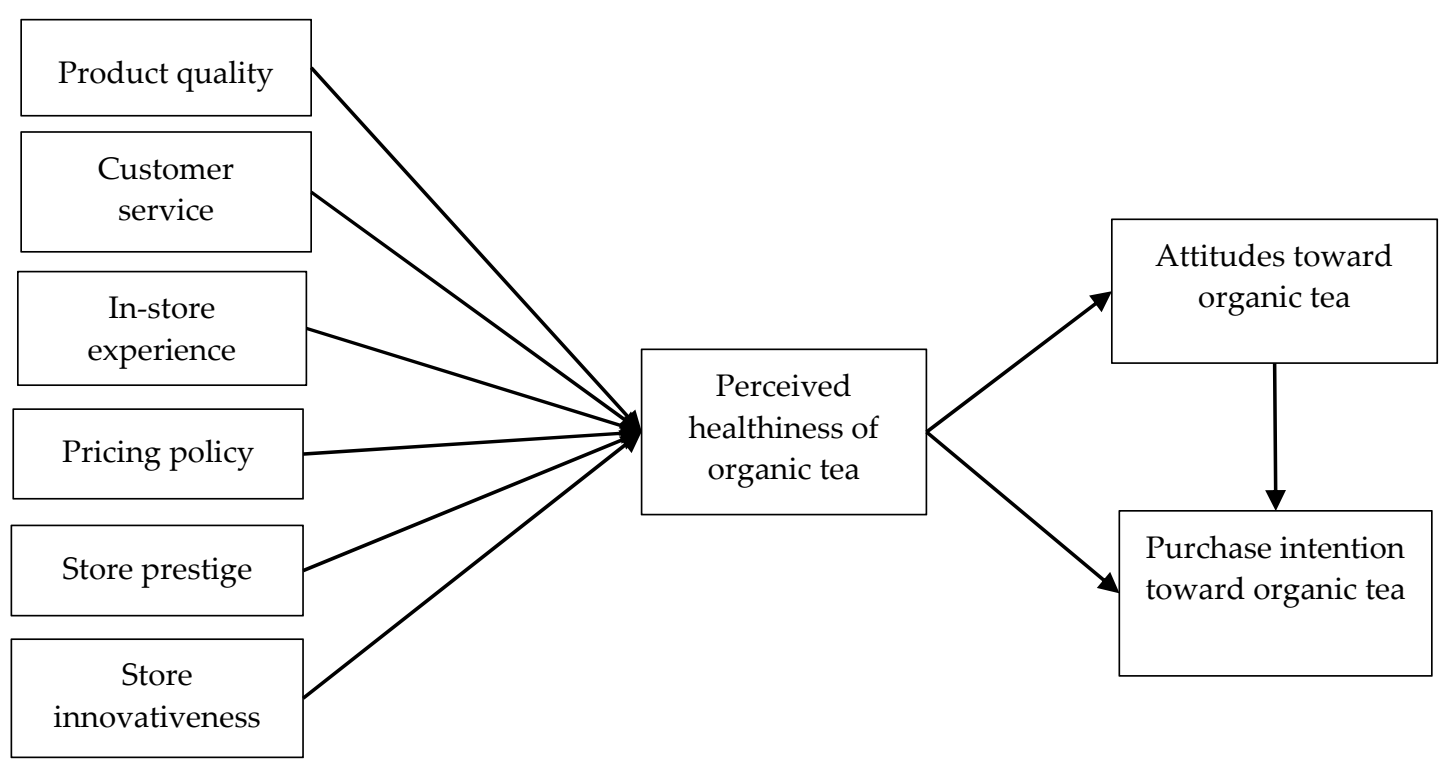

Figure 1. Research model.

\section{Research Methods}

\subsection{Questionnaire Design}

To test the hypotheses in this study, we conducted a survey to collect sample data. The items of the questionnaire were adopted from studies in current literature. We used a 5-point Likert scale from strongly disagree (1) to strongly agree (5) to measure all items. Details of the constructs and items of the measures in this study are present in Table 1.

Table 1. Constructs and items.

\begin{tabular}{|c|c|c|}
\hline Constructs & Items & Sources \\
\hline Customer service & $\begin{array}{l}\text { "Store personnel are kind and helpful." } \\
\text { "Salespeople have a good knowledge of the products." } \\
\text { "This store offers a high level of customer service." }\end{array}$ & [49] \\
\hline Pricing policy & $\begin{array}{l}\text { "You get good value for your money." } \\
\text { "The relationship between price and quality is good" }\end{array}$ & [49] \\
\hline \multirow{3}{*}{ In-store shopping experience } & $\begin{array}{l}\text { "The store smells good inside." } \\
\text { "The store's interior is well designed." } \\
\text { "The store lighting displays products well." } \\
\text { "The store's music is in harmony with the store image." } \\
\text { "Shoppers can choose products comfortably at the store." } \\
\text { "I feel happy when shopping at the store." } \\
\text { "I feel refreshed when shopping at the store." } \\
\text { "I feel relaxed when shopping at the store." } \\
\text { "I feel fulfilled when shopping at the store." }\end{array}$ & \multirow{3}{*}[50]{} \\
\hline & "The store gets me interested in shopping." & \\
\hline & $\begin{array}{l}\text { "The store provides me with new information on product." } \\
\text { "The store gives me a positive image about it." } \\
\text { "The store fits with my lifestyle." } \\
\text { "I like to take part in the events or activities of the store." } \\
\text { "I like to buy products from the store if it has what I want." } \\
\text { "I like to have a membership card issued by the store." } \\
\text { "I like to use the information and service the store offers me." } \\
\text { "I like to continue store patronage because of the store employees." } \\
\text { "I am very satisfied with the store." }\end{array}$ & \\
\hline
\end{tabular}


Table 1. Cont.

\begin{tabular}{|c|c|c|}
\hline Constructs & Items & Sources \\
\hline Store innovativeness & $\begin{array}{l}\text { "This store offers many new products." } \\
\text { "This store offers innovative private brand products." } \\
\text { "This store offers many innovative services." } \\
\text { "This store offers an innovative shopping environment." } \\
\text { "This store offers innovative promotions." }\end{array}$ & [37] \\
\hline Store prestige & $\begin{array}{l}\text { "This store is very prestigious." } \\
\text { "This store has high status." } \\
\text { "This store is very upscale." }\end{array}$ & [37] \\
\hline Perceived healthiness & $\begin{array}{l}\text { "This store provides fresh organic tea." } \\
\text { "This store sells organic tea products." } \\
\text { "This store serves natural tea products." } \\
\text { "Healthy tea products are sold in this store." }\end{array}$ & [37] \\
\hline Attitude toward organic tea & $\begin{array}{c}\text { "Purchasing organic tea is desirable because it is socially responsible products." } \\
\text { "Purchasing organic tea is desirable because it is more beneficial to society's } \\
\text { welfare than other drinking products." } \\
\text { "Purchasing organic tea is desirable because it contributes something to society." }\end{array}$ & {$[51]$} \\
\hline Organic tea purchase intention & $\begin{array}{l}\text { "I am willing to buy organic tea while shopping." } \\
\text { "I will make an effort to buy organic tea in the near future." } \\
\text { "I intend to buy organic tea because they are more environmentally friendly." }\end{array}$ & [52] \\
\hline
\end{tabular}

\subsection{Sample Procedure}

The survey in this study was conducted at different tea stores in Guangdong province in China. Guangdong is known as the largest province with a population of more than 110 million people. Drinking tea is a traditional cultural custom in Guangdong. Tea stores are open everywhere to satisfy residents' demands. Therefore, we randomly selected 15 large stores and invited customers in these stores to participate the survey. Customers are conveniently asked to compete the questionnaire. We offer each consumer a small gift to increase their willingness. Consumers voluntarily participate the survey. A total of 800 questionnaires were randomly delivered to customers. 620 questionnaires were returned, and 618 questionnaires were valid with a response rate of $77.25 \%$. Only two questionnaires were excluded from final data due to missing value. Table 2 shows the demographics of respondents in this study.

\subsection{Ethical Consideration}

The survey in this study was administered to customers at different tea stores in China. Ethical standard should be considered due to the survey is related to human activities. Therefore, we invited only customers who voluntarily participated the survey. Customers also anonymously completed the questionnaire without privacy concerns. Furthermore, the protocols for data collection was approved by Key Research Projects of National Social Science Foundation of China (Grant No. 16AGL010). Thus, ethical standard was carefully considered in this study.

\subsection{Analytical Methods}

The sample data in this study were analyzed using SPSS and AMOS statistical software. First, we used SPSS to screen the data and analyzed descriptive statistics and reliability (reliability analysis). Second, we used AMOS to perform a confirmatory factor analysis (CFA). Convergent and discriminant validity were tested using results of this CFA model. Third, all the hypotheses were tested in a single model using Partial Least Square Structural Equation Modeling (PLS-SEM). 
Table 2. Demographics of respondents.

\begin{tabular}{ccc}
\hline Variable & Frequency & Percent \\
\hline Gender & 214 & \\
Male & 404 & $34.60 \%$ \\
Female & & $65.40 \%$ \\
Age & 30 & \\
25 or below & 297 & $4.90 \%$ \\
$26-35$ & 201 & $48.10 \%$ \\
$36-45$ & 78 & $32.50 \%$ \\
$46-55$ & 12 & $12.60 \%$ \\
56 or above & & $1.90 \%$ \\
Marital status & 584 & \\
Married & 34 & $94.50 \%$ \\
Not married & & $5.50 \%$ \\
Income & 203 & $32.80 \%$ \\
Under 3000 RMB & 248 & $40.10 \%$ \\
3000-under 6000 RMB & 100 & $16.20 \%$ \\
6000-under 9000 RMB & 44 & $7.10 \%$ \\
9000-under 12,000 RMB & 23 & $3.70 \%$ \\
12,000 RMB or above & & \\
Yot purchase organic tea before? & 435 & $70.40 \%$ \\
Yes & 183 & $29.60 \%$ \\
\hline No & &
\end{tabular}

Note: $\mathrm{n}=618$.

\section{Results}

\subsection{Reliability and Validity}

Table 3 shows the results of confirmatory factor analysis for the measures in this study. Results indicate that all indicators met the requirement for a good model fit $\left(\chi^{2} /\right.$ d.f. $=2299.51 / 879=2.62$, $\mathrm{GFI}=0.92, \mathrm{CFI}=0.94, \mathrm{NFI}=0.91$, and RMSEA $=0.05)[53]$.

Table 3. Goodness of fit.

\begin{tabular}{|c|c|c|c|c|c|c|}
\hline Constructs/Model & $x^{2} /$ d.f. & $p$-Value & GFI & CFI & NFI & RMSEA \\
\hline Thresholds & $<3$ & $>0.05$ & $>0.90$ & $>0.90$ & $>0.90$ & $<0.08$ \\
\hline $\begin{array}{l}\text { Hypothesized } \\
\text { Model }\end{array}$ & $2299.51 / 879$ & 0.000 & 0.92 & 0.94 & 0.91 & 0.05 \\
\hline
\end{tabular}

According to Kline [53], we used Cronbach's Alpha $(\alpha)$ to examine the reliability of the measures. Accordingly, Cronbach's $\alpha$ must be greater than 0.60 . Results in Table 4 show that Cronbach's $\alpha$ ranged from 0.77 to 0.96 , indicating a good reliability of the measures.

Furthermore, Hair et al. [54] asserted that, to ensure convergent validity, composite reliability (CR) must be higher than 0.70 and average variance extracted (AVE) must be greater than 0.50 , the. Results in Table 4 indicate that all CR values and AVE values met the thresholds, supporting the assumption of good convergent validity of the measures in this study. 
Table 4. Confirmatory factor analysis and Cronbach's Alpha.

\begin{tabular}{|c|c|c|c|c|c|c|}
\hline Constructs & Items & Loadings & CR & AVE & $\sqrt{ }$ AVE & Cronbach's $\alpha$ \\
\hline \multirow{4}{*}{ Product quality (PQ) } & PQ1 & $0.81^{* * *}$ & \multirow{4}{*}{0.78} & \multirow{4}{*}{0.54} & \multirow{4}{*}{0.74} & \multirow{4}{*}{0.77} \\
\hline & PQ2 & $0.82 * * *$ & & & & \\
\hline & PQ3 & $0.55^{* * *}$ & & & & \\
\hline & $\widehat{\mathrm{CS}} 1$ & $0.89 * * *$ & & & & \\
\hline \multirow[t]{2}{*}{ Customer service (CS) } & $\mathrm{CS} 2$ & $0.86^{* * *}$ & \multirow[t]{2}{*}{0.89} & \multirow[t]{2}{*}{0.73} & \multirow[t]{2}{*}{0.85} & \multirow[t]{2}{*}{0.89} \\
\hline & CS3 & $0.81 * * *$ & & & & \\
\hline \multirow{11}{*}{ Pricing policy (PP) } & PP1 & $0.86^{* * *}$ & \multirow{11}{*}{0.82} & \multirow{11}{*}{0.69} & \multirow{11}{*}{0.83} & \multirow{11}{*}{0.87} \\
\hline & PP2 & $0.81^{* * *}$ & & & & \\
\hline & SE1 & $0.72 * * *$ & & & & \\
\hline & SE2 & $0.75^{* * *}$ & & & & \\
\hline & SE3 & $0.69 * * *$ & & & & \\
\hline & SE4 & $0.71^{* * *}$ & & & & \\
\hline & SE5 & $0.78^{* * *}$ & & & & \\
\hline & SE6 & $0.79 * * *$ & & & & \\
\hline & SE7 & $0.81^{* * *}$ & & & & \\
\hline & SE8 & $0.78^{* * *}$ & & & & \\
\hline & SE9 & $0.81^{* * *}$ & & & & \\
\hline \multirow[t]{12}{*}{ In-store shopping experience (SE) } & SE10 & $0.79 * * *$ & \multirow[t]{12}{*}{0.96} & \multirow[t]{12}{*}{0.56} & \multirow[t]{12}{*}{0.75} & \multirow[t]{12}{*}{0.96} \\
\hline & SE11 & $0.76^{* * *}$ & & & & \\
\hline & SE12 & $0.77^{* * *}$ & & & & \\
\hline & SE13 & $0.76^{* * *}$ & & & & \\
\hline & SE14 & $0.70 * * *$ & & & & \\
\hline & SE15 & $0.72 * * *$ & & & & \\
\hline & SE16 & $0.61^{* * *}$ & & & & \\
\hline & SE17 & $0.73^{* * *}$ & & & & \\
\hline & SE18 & $0.67^{* * *}$ & & & & \\
\hline & SE19 & $0.79 * * *$ & & & & \\
\hline & SI1 & $0.87^{* * *}$ & & & & \\
\hline & SI2 & $0.94^{* * *}$ & & & & \\
\hline \multirow[t]{4}{*}{ Store innovativeness (SI) } & SI3 & $0.92 * * *$ & \multirow[t]{4}{*}{0.93} & \multirow[t]{4}{*}{0.73} & 0.85 & 0.93 \\
\hline & SI4 & $0.76^{* * *}$ & & & & \\
\hline & SI5 & $0.76^{* * *}$ & & & & \\
\hline & SP1 & $0.64^{* * *}$ & & & & \\
\hline Store prestige (SP) & SP2 & $0.78^{* * *}$ & 0.83 & 0.62 & 0.79 & 0.87 \\
\hline & SP3 & $0.92 * * *$ & & & & \\
\hline & PH1 & $0.92 * * *$ & & & & \\
\hline Perceived healthinese (PH) & PH2 & $0.92^{* * *}$ & & & & \\
\hline Perceived healthiness (PH) & PH3 & $0.90 * * *$ & 0.94 & 0.80 & 0.90 & 0.95 \\
\hline & PH4 & $0.84^{* * *}$ & & & & \\
\hline & AT1 & $0.92 * * *$ & & & & \\
\hline Attitude (AT) & AT2 & $0.94^{* * *}$ & 0.93 & 0.82 & 0.90 & 0.93 \\
\hline & AT3 & $0.85^{* * *}$ & & & & \\
\hline & PI1 & $0.88^{* * *}$ & & & & \\
\hline Purchase Intention (PI) & PI2 & $0.87 * * *$ & 0.91 & 0.77 & 0.88 & 0.91 \\
\hline & PI3 & $0.89 * * *$ & & & & \\
\hline
\end{tabular}

Note: $\mathrm{n}=618^{* * *} p<0.001$.

In addition, following Hair et al.'s [54] suggestion, discriminant validity is tested by comparing the square roots of AVE and correlation coefficients of all variables. Results in Table 5 show that all correlation coefficients were less than all square roots of AVE, thereby providing evidence for a good discriminant validity of the measures in this study. 
Table 5. Means, Standard Deviations, Minimum, and Maximum values of variables.

\begin{tabular}{ccccc}
\hline Variable & Means & Standard Deviations & Minimum & Maximum \\
\hline 1. PQ & 5.37 & 0.98 & 1.00 & 7.00 \\
2. CS & 5.23 & 1.14 & 1.00 & 7.00 \\
3. PP & 5.07 & 1.01 & 1.00 & 7.00 \\
4. SE & 5.18 & 0.86 & 1.00 & 7.00 \\
5. SI & 5.02 & 1.08 & 1.00 & 7.00 \\
6. SP & 5.07 & 1.00 & 1.00 & 7.00 \\
7. PH & 5.50 & 1.02 & 1.00 & 7.00 \\
8. AT & 5.19 & 1.07 & 1.00 & 7.00 \\
9. PI & 5.42 & 0.99 & 1.00 & 7.00 \\
\hline
\end{tabular}

Note: $\mathrm{n}=618, \mathrm{PQ}=$ product quality, $\mathrm{CS}=$ customer service, $\mathrm{PP}=$ price policy, $\mathrm{SE}=$ in-store shopping experience, $\mathrm{SI}=$ store innovativeness, $\mathrm{SP}=$ store prestige, $\mathrm{PH}=$ perceived healthiness, $\mathrm{AT}=$ attitude, $\mathrm{PI}=$ purchase intention.

Table 6 shows the descriptive statistics for all variables in this study.

Table 6. Pearson Correlations.

\begin{tabular}{lccccccccc}
\hline Variable & $\mathbf{1}$ & $\mathbf{2}$ & $\mathbf{3}$ & $\mathbf{4}$ & $\mathbf{5}$ & $\mathbf{6}$ & $\mathbf{7}$ & $\mathbf{8}$ & $\mathbf{9}$ \\
\hline 1. PQ & $\mathbf{0 . 7 4}$ & & & & & & & & \\
2. CS & $0.47^{* *}$ & $\mathbf{0 . 8 5}$ & & & & & & & \\
3. PP & $0.36^{* *}$ & $0.46^{* *}$ & $\mathbf{0 . 8 3}$ & & & & & & \\
4. SE & $0.46^{* *}$ & $0.65^{* *}$ & $0.58^{* *}$ & $\mathbf{0 . 7 5}$ & & & & & \\
5. SI & $0.40^{* *}$ & $0.59^{* *}$ & $0.47^{* *}$ & $0.58^{* *}$ & $\mathbf{0 . 8 5}$ & & & & \\
6. SP & $0.43^{* *}$ & $0.51^{* *}$ & $0.47^{* *}$ & $0.50^{* *}$ & $0.61^{* *}$ & $\mathbf{0 . 7 9}$ & & & \\
7. PH & $0.42^{* *}$ & $0.55^{* *}$ & $0.45^{* *}$ & $0.66^{* *}$ & $0.64^{* *}$ & $0.59^{* *}$ & $\mathbf{0 . 9 0}$ & & \\
8. AT & $0.41^{* *}$ & $0.39^{* *}$ & $0.44^{* *}$ & $0.53^{* *}$ & $0.51^{* *}$ & $0.50^{* *}$ & $0.44^{* *}$ & $\mathbf{0 . 9 0}$ & \\
9. PI & $0.50^{* *}$ & $0.44^{* *}$ & $0.46^{* *}$ & $0.61^{* *}$ & $0.52^{* *}$ & $0.57^{* *}$ & $0.59^{* *}$ & $0.65^{* *}$ & $\mathbf{0 . 8 8}$
\end{tabular}

Note: $\mathrm{n}=618,{ }^{* *} p<0.01$, square roots of AVE calculated for each of the constructs are along the diagonal. $\mathrm{PQ}=$ product quality, $\mathrm{CS}=$ customer service, $\mathrm{PP}=$ price policy, $\mathrm{SE}=\mathrm{In}$-store shopping experience, $\mathrm{SI}=$ store innovativeness, $\mathrm{SP}=$ store prestige, $\mathrm{PH}=$ perceived healthiness, $\mathrm{AT}=$ attitude, $\mathrm{PI}=$ purchase intention.

\subsection{Testing Common Method Bias}

According to Podsakoff at al. [55], results of hypothesis testing may be influenced by the common method bias due to data are collected for all variables at the same time from the same respondents. To test this problem, we performed Harman's one factor test with an exploratory factor analysis. Results of unrotated solution show solution of 9 factors with $72.28 \%$ of variance and the first factor accounted for only $21.39 \%$ of variance. Results of a one-factor CFA show a poor model fit which provide evidence to confirm the results of the Harman's test $\left(\chi^{2} /\right.$ d.f. $=9810.66 / 945=10.38, \mathrm{GFI}=0.51$, $\mathrm{CFI}=0.64, \mathrm{NFI}=0.61$, and RMSEA $=0.12$ ). Thus, common method bias may be ignored in this study.

\subsection{Hypothesis Testing}

Results of PLS-SEM used to test the proposed hypotheses are presented in Figure 2. According to Figure 2 , product quality $(\beta=0.077, p<0.01)$, customer service $(\beta=0.094, p<0.01)$, in-store shopping experience $(\beta=0.263, p<0.001)$, store innovativeness $(\beta=0.284, p<0.001)$, and store prestige $(\beta=0.138, p<0.001)$ all had a positive impact on perceived healthiness of organic tea. Thus, hypotheses $\mathrm{H} 1, \mathrm{H} 2, \mathrm{H} 4, \mathrm{H} 5$, and $\mathrm{H} 6$ were supported. High pricing policy, however, was not significantly related to perceived healthiness of organic tea $(\beta=0.025$, ns.), thereby hypothesis $\mathrm{H} 3$ was not supported. Furthermore, results in Figure 2 indicate that perceived healthiness of organic tea had a positive influence on purchase intention $(\beta=0.373, p<0.001)$. Thus, hypothesis H7 was supported. 


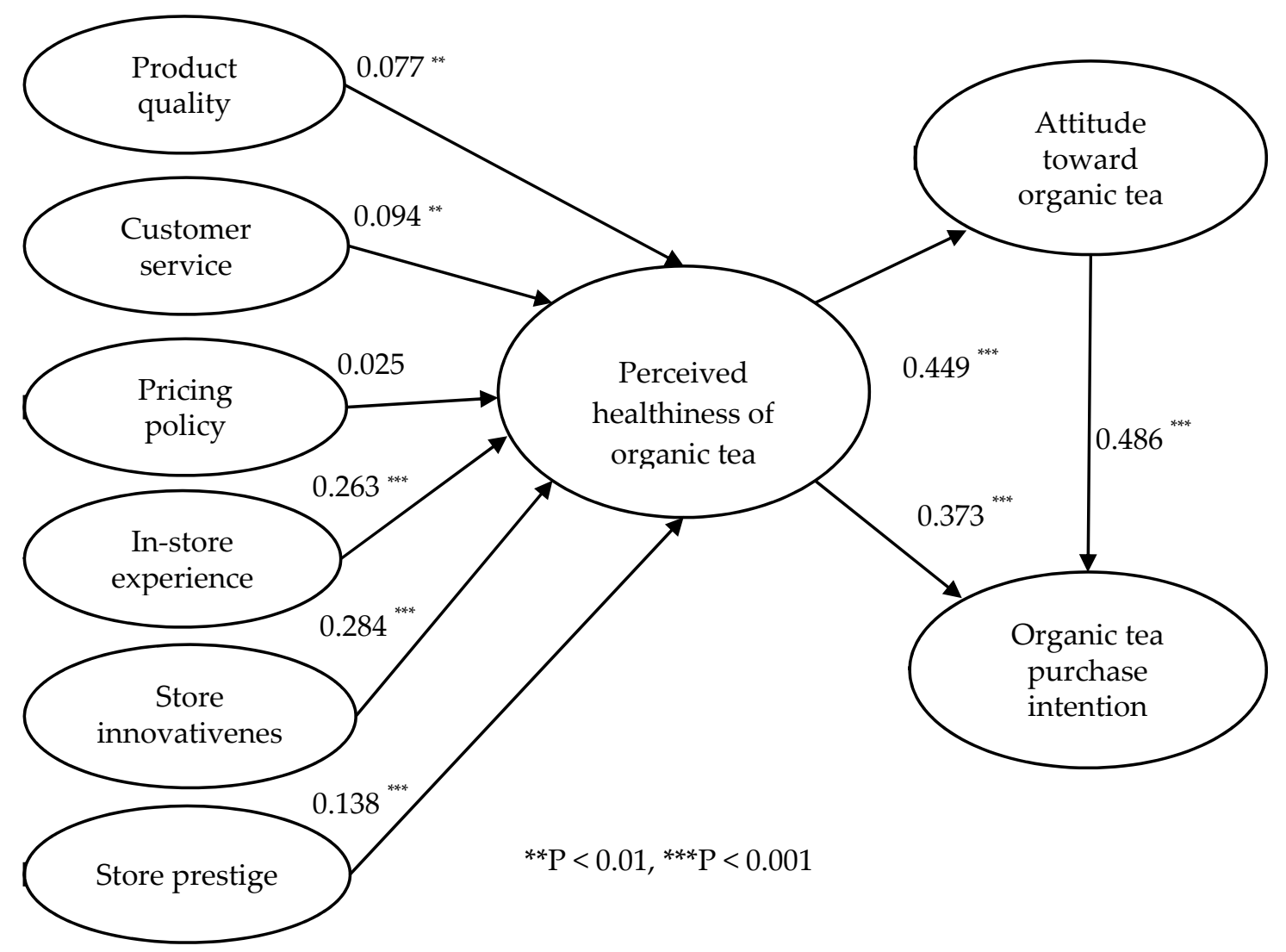

Figure 2. Results of structural equation model.

As expected, perceived healthiness of organic tea was positively associated with attitude toward organic tea $(\beta=0.449, p<0.001)$ which in turn was positively associated with purchase intention $(\beta=$ $0.486, p<0.001)$. To confirm this indirect effect, we followed Preacher et al. [56] to conduct a bootstrap analysis. Results of 1000 bootstrap samples show that the indirect effect of perceived healthiness of organic tea on organic tea purchase intention via attitude toward organic tea was statistically significant $(\beta=0.211, p<0.01,95 \% \mathrm{CI}=[0.160-0.279])$. Thus, hypothesis H8 was supported.

\section{Discussions and Implications}

This study seeks to contribute to the literature relating to organic food consumption and sustainable behaviors by investigating the antecedents and outcomes of consumer perceived healthiness or organic tea. Specifically, it examines different marketing factors that predict consumer perceived healthiness of organic tea, and the relationship between perceived healthiness and purchase intention with the mediating role of attitude toward organic tea. Results of empirical analysis indicate that product quality, customer service, in-store experience, store innovativeness, and store prestige altogether enhance consumer perceived healthiness of organic tea. That is, except high price policy, all other variables significantly and positively predict consumers' perceptions of the healthiness of organic tea. Store innovativeness and in-store experience have the highest impact on perceived healthiness of organic tea. These results imply that when consumers purchase organic tea, they not only focus on the product itself but also care about the innovativeness of the stores and their shopping experience. This is because consumers have too much choices of products in today's business environment. Consumers tend to seek for the pleasure in their shopping trips and they also demand newness and novelty from physical stores $[34,35]$. Furthermore, high price policy has no significant influence on consumers' perceptions of healthiness of organic tea. This can be explained by the fact that consumers who prefer organic tea don't rely on price to evaluate the value of organic tea. Consumers may not care about high price of organic tea due to their purchase power and income increase. Organic tea is also daily consuming product, 
its high price may be acceptable for consumers as compare with price of other types of products. Furthermore, perceived healthiness appears to have a positive influence on purchase intention toward organic tea. Notably, attitudes mediated the relationship between perceived healthiness and purchase intention toward organic tea. Based on these findings, this study provides implications for researchers and business managers.

\subsection{Theoretical Implications}

Consumers have been increasingly interested in organic tea in recent years. Demands for organic tea have increased rapidly not only in China market but also the global market $[3,6]$. Despite the importance of organic tea in consumers' daily life and its large potential market, very few studies have determined consumer behavior in tea industry and tea consumption. This study fills research gap in current literature by investigating antecedents of consumer perceived healthiness of organic tea. The findings indicate that various marketing factors influencing consumer perceived healthiness of organic tea include product quality, customer service, in-store experience, store innovativeness, and store prestige. These findings imply that consumers' evaluation of organic tea depends not only on tea product itself but also other factors of tea stores. Therefore, this study enriches knowledge in current organic tea literature and provides implication for marketing research in tea industry.

This study finds a positive association between perceived healthiness and purchase intention toward organic tea, which is in line with the study conducted by Sumi et al. [6]. This finding suggests that consumer perception of healthiness is an important factor in the purchase decisions toward organic tea. That is, consumers often perceive organic tea as safer and healthier than other types of tea products. Consumers also feel that organic tea has less negative impact on environment because organic tea is cultivated and processed without fertilizers, chemicals, and pesticides. With the perceptions of the benefit of organic tea to human health and environment, consumers tend to hold high intention to purchase organic tea. Thus, this study sheds a new light on the relationship between perceived healthiness and purchase intention toward organic tea. This finding may be of interest to researchers who wish to understand the issue of healthiness and purchase behavior toward organic tea.

The findings also indicate that perceptions of healthiness positively influenced consumers' attitudes which in turn positively affected purchase intention toward organic tea. In other words, when consumers perceive organic tea as safe and healthy products, they tend to form positive attitudes and take action to purchase organic tea. This finding enriches current literature emphasizing the roles of health consciousness and health benefits in organic food consumption [57-62]. Importantly, it provides fresh insight into the mediating mechanism of consumer attitudes in the link between consumers' perceptions of healthiness and purchase intention toward organic tea. Thus, this finding may have implication for researchers who will study the mediating and/or moderating mechanism in the relationship between consumers' perceptions and behavior in organic tea consumption.

Finally, although China has been the largest tea market in the world, very limited studies have determined the issue of organic tea consumption in China. This study contributes to the extant literature relating to sustainable food consumption by providing evidence on consumer behavior toward organic tea consumption in China. To our best knowledge, this study is one of the most comprehensive research that provides insights into the antecedents of perceived healthiness and its relationship with purchase intention with the mediating effect of consumer attitudes toward organic tea in China market. Thus, this study provides initial evidence to advance our knowledge about consumer behavior toward organic tea in China.

\subsection{Practical Implications}

Several implications for business managers are also proposed based on our findings. It is suggested that tea stores should have strategy to raise consumers' perceptions of healthiness of organic tea. For example, managers should plan and execute marketing strategy to deliver signal of high product quality of organic tea to consumers. Marketing advertising should differentiate the product quality 
between organic tea and other types of tea products. Specifically, organic tea has superior product quality than other tea products.

At the same time, in order to satisfy consumers' demand, tea retail stores should use different methods to enhance their service quality. For example, managers should improve their customer service by training their service personnel. Professional salesperson will provide high quality of service and advance consumers' knowledge about organic tea. Tea stores should also use advanced technology to help consumers during their shopping (e.g., an advance payment system may reduce consumers' time of waiting).

Furthermore, managers should invest to improve tea stores' shopping environment and innovativeness to create more shopping experience for consumers. For example, tea stores should focus their attention to store environment to improve quality of indoor environment (e.g., quality of air, layout, thermal, and acoustic environment of tea stores). Besides, tea stores also should innovate to create more value for consumers. For example, tea stores may develop new products, create new package, or innovate their service strategy. By improve store environment and innovative more new products and service for consumers, tea stores can enhance consumers' in-store shopping experience when they purchase at tea stores.

In addition, a marketing strategy to build store prestige is also necessary to create a favorable image in the eyes of consumers. To persuade consumers purchase organic tea, business managers should also plan marketing strategy to shape consumers' positive attitudes toward organic tea. For example, advertising strategy should emphasize the benefits of organic tea that bring safety and healthiness for human health. With appropriate marketing and advertising strategy, tea stores may improve consumers' perceptions, attitudes, and behavior toward organic tea.

Policy makers should also play an important role in communicating and promoting health-related benefits of organic food in general and organic tea in particular. Informational and educational programs should be implemented to deliver a clear message about the healthiness of organic tea, its ability to increase metabolism and how it can reduce depression risks. Such programs should be co-developed and co-implemented with organic food manufacturers, retailers, universities and schools.

\section{Limitations and Future Research}

This study has several limitations that should be addressed in future research. This study was conducted in the context of Chinese tea stores and Chinese consumers. This may affect the generalizability of the findings. Future research should collect data from other countries like India and those in Southeast Asia to further explain consumer behavior in tea industry. These countries are also the major producers of tea in the world. Furthermore, cross-sectional data in this study may lead to common variance bias, given that sample data were collected at a point of time. This could influence the results of hypothesis testing in this study. Hence longitudinal study can be conducted to collect data from consumer at different points of time to avoid common method variance problems. In addition, the measure of high price policy in this study was adopted from Anselmsson, Burt, and Tunca [49]. The items reflect the price that represents the value of the products: "you get good value for your money" and "the relationship between price and quality is good". These items indicate that the higher the price is the higher the value the product has. Although the items from Anselmsson et al. [49] has been tested to have high reliability and validity, it measures the relationship between price and value of a product. This may be a limitation that inherent in prior studies and this study. Thus, future research should develop better measurement items to reflect the meaning of price policy. Finally, future research can extend this study's research model by including additional factors that may affect consumer intention to purchase organic tea, such as emotions and social influences.

Author Contributions: Conceptualization: X.B., H.V.N., T.P.C., C.-P.C.; methodology: X.B., H.V.N., T.P.C., C.-P.C.; formal analysis: X.B., H.V.N., T.P.C., C.-P.C.; investigation: X.B., H.V.N., T.P.C., C.-P.C.; resources: X.B.; writing—original draft preparation: X.B., H.V.N., T.P.C., C.-P.C.; writing—review and editing: X.B., H.V.N., T.P.C., C.-P.C. All authors have read and agreed to the published version of the manuscript. 
Funding: This research received funding from the Key Research Projects of National Social Science Foundation of China (Grant No. 16AGL010).

Conflicts of Interest: The authors declare that they have no conflict of interest.

\section{References}

1. Ho, C.T.; Lin, J.K.; Shahidi, F. Tea and Tea Products: Chemistry and Health-Promoting Properties; CRC Press: London, UK, 2008.

2. Rothenberg, D.O.; Zhang, L. Mechanisms Underlying the Anti-Depressive Effects of Regular Tea Consumption. Nutrients 2019, 11, 1361. [CrossRef] [PubMed]

3. Global Market Report. Sustainable Commodities Marketplace Series 2019. 2020. Available online: https://www.iisd.org/sites/default/files/publications/ssi-global-market-report-tea.pdf (accessed on 24 June 2020).

4. Da Silva Pinto, M. Tea: A new perspective on health benefits. Food Res. Int. 2013, 53, 558-567. [CrossRef]

5. Legeay, S.; Rodier, M.; Fillon, L.; Faure, S.; Clere, N. Epigallocatechin gallate: A review of its beneficial properties to prevent metabolic syndrome. Nutrients 2015, 7, 5443-5468. [CrossRef] [PubMed]

6. Sumi, R.S.; Kabir, G. Factors affecting the buying intention of organic tea consumers of Bangladesh. J. Open Innov. Technol. Mark. Complex. 2018, 4, 24. [CrossRef]

7. Bagchi, A.; Ghosh, B.C.; Swain, D.K.; Bera, N. Organic farming practice for quality improvement of tea and its anti Parkinsonism effect on health defense. J. Phys. Chem. Biophys. 2015, 5, 2161. [CrossRef]

8. Hazra, N.G. Organic Tea: Cultivation and Marketing; International Book Distributors: Dehra Dun, India, 2006.

9. Jensen, J.D.; Christensen, T.; Denver, S.; Ditlevsen, K.; Lassen, J.; Teuber, R. Heterogeneity in consumers' perceptions and demand for local (organic) food products. Food Qual. Prefer. 2019, 73, 255-265. [CrossRef]

10. Chen, M.-F. Attitude toward organic foods among Taiwanese as related to health consciousness, environmental attitudes, and the mediating effects of a healthy lifestyle. Br. Food J. 2009, 111, 165-178. [CrossRef]

11. Chekima, B.; Chekima, K.; Chekima, K. Understanding factors underlying actual consumption of organic food: The moderating effect of future orientation. Food Qual. Prefer. 2019, 74, 49-58. [CrossRef]

12. Hoffmann, S.; Schlicht, J. The impact of different types of concernment on the consumption of organic food. Int. J. Consum. Stud. 2013, 37, 625-633. [CrossRef]

13. Huy, L.V.; Chi, M.T.T.; Lobo, A.; Nguyen, N.; Long, P.H. Effective segmentation of organic food consumers in Vietnam using food-related lifestyles. Sustainability 2019, 11, 1237.

14. Michaelidou, N.; Hassan, L.M. The role of health consciousness, food safety concern and ethical identity on attitudes and intentions towards organic food. Int. J. Consum. Stud. 2008, 32, 163-170. [CrossRef]

15. O'Donovan, P.; McCarthy, M. Irish consumer preference for organic meat. Br. Food J. 2002, 104, 353-370. [CrossRef]

16. Verhoef, P.C. Explaining purchases of organic meat by Dutch consumers. Eur. Rev. Agric. Econ. 2005, 32, 245-267.

17. Hill, H.; Lynchehaun, F. Organic milk: Attitudes and consumption patterns. Br. Food J. 2002, 104, 526-542. [CrossRef]

18. Carfora, V.; Cavallo, C.; Caso, D.; Del Giudice, T.; De Devitiis, B.; Viscecchia, R.; Nardone, G.; Cicia, G. Explaining consumer purchase behavior for organic milk: Including trust and green self-identity within the theory of planned behavior. Food Qual. Prefer. 2019, 76, 1-9. [CrossRef]

19. Haghiri, M.; Hobbs, J.E.; McNamara, M.L. Assessing consumer preferences for organically grown fresh fruit and vegetables in Eastern New Brunswick. Int. Food Agribus. Manag. Rev. 2009, 12, 81-100.

20. Mohd Suki, N. Determinants of consumers' purchase intentions of organic vegetables: Some insights from Malaysia. J. Food Prod. Mark. 2017, 24, 1-21. [CrossRef]

21. Liu, S.; Li, Z.; Sui, Y.; Schaefer, D.A.; Alele, P.O.; Chen, J.; Yang, X. Spider foraging strategies dominate pest suppression in organic tea plantations. BioControl 2015, 60, 839-847. [CrossRef]

22. Qiao, Y.; Halberg, N.; Vaheesan, S.; Scott, S. Assessing the social and economic benefits of organic and fair-trade tea production for small-scale farmers in Asia: A comparative case study of China and Sri Lanka. Renew. Agric. Food Syst. 2016, 31, 246-257. [CrossRef] 
23. Nguyen, N.; Nguyen, H.V.; Nguyen, P.T.; Tran, V.T.; Nguyen, H.N.; Nguyen, T.M.N.; Cao, T.K.; Nguyen, T.H. Some key factors affecting consumers' intentions to purchase functional foods: A case study of functional yogurts in Vietnam. Foods 2020, 9, 24.

24. Hasimu, H.; Marchesini, S.; Canavari, M. A concept mapping study on organic food consumers in Shanghai, China. Appetite 2017, 108, 191-202. [CrossRef] [PubMed]

25. Pham, T.H.; Nguyen, T.N.; Phan, T.T.H.; Nguyen, N.T. Evaluating the purchase behaviour of organic food by young consumers in an emerging market economy. J. Strateg. Mark. 2019, 27, 540-556. [CrossRef]

26. Wang, J.; Nguyen, N.; Bu, X. Exploring the roles of green food consumption and social trust in the relationship between perceived consumer effectiveness and psychological wellbeing. Int. J. Env. Res. Public Health 2020, 17, 4676. [CrossRef] [PubMed]

27. Hinsch, B. The Rise of Tea Culture in China: The Invention of the Individual; Rowman \& Littlefield: New York, NY, USA, 2016.

28. Wang, N. A comparison of Chinese and British tea culture. Asian Cult. Hist. 2011, 3, 13. [CrossRef]

29. Wang, L. Tea and Chinese Culture; Long River Press: San Francisco, CA, USA, 2005.

30. Loebnitz, N.; Aschemann-Witzel, J. Communicating organic food quality in China: Consumer perceptions of organic products and the effect of environmental value priming. Food Qual. Prefer. 2016, 50, 102-108. [CrossRef]

31. Suciu, N.A.; Ferrari, F.; Trevisan, M. Organic and conventional food: Comparison and future research. Trends Food Sci. Technol. 2019, 84, 49-51. [CrossRef]

32. James, M.X.; Hu, Z.; Leonce, T.E. Predictors of organic tea purchase intentions by Chinese consumers. J. Agribus. Dev. Emerg. Econ. 2019, 9, 202-219. [CrossRef]

33. Han, Y. Study on consumption behavior of milk tea based on the customer value theory-Taking "A little tea" in Shenzhen as an example. In Proceedings of the 2018 International Conference on Management, Economics, Education and Social Sciences (MEESS 2018), Shanghai, China, 11-12 August 2018.

34. Levy, M.; Weitz, B. Retailing Management; McGraw-Hill Education: Stanford, CA, USA, 2016.

35. Kotler, P.; Armstrong, G. Principles of Marketing; Pearson Education: London, UK, 2018.

36. Lee, K.H.; Bonn, M.A.; Cho, M. Consumer motives for purchasing organic coffee. Int. J. Contemp. Hosp. Manag. 2015, 27, 1157-1180. [CrossRef]

37. Konuk, F.A. The impact of retailer innovativeness and food healthiness on store prestige, store trust and store loyalty. Food Res. Int. 2019, 116, 724-730. [CrossRef]

38. Lam, S.Y. The effects of store environment on shopping behaviors: A critical review. Adv. Consum. Res. 2001, 28, 190-197.

39. Kim, S.; Ham, S.; Moon, H.; Chua, B.L.; Han, H. Experience, brand prestige, perceived value (functional, hedonic, social, and financial), and loyalty among GROCERANT customers. Int. J. Hosp. Manag. 2019, 77, 169-177. [CrossRef]

40. Lin, C.Y. Perceived convenience retailer innovativeness: How does it affect consumers? Manag. Decis. 2016, 54, 946-964. [CrossRef]

41. Ruiz-Molina, M.E.; Gil-Saura, I.; Berenguer-Contrí, G. Are retailers' perceptions of their innovativeness and technology similar to those of consumers? In Handbook of Research on Retailing Techniques for Optimal Consumer Engagement and Experiences; IGI Global: Hershey, PA, USA, 2020; pp. 310-337.

42. Lin, C.Y. How does perceived retail service innovativeness affect retail patronage intentions? Creat. Innov. Manag. 2019, 28, 519-532. [CrossRef]

43. Provencher, V.; Jacob, R. Impact of perceived healthiness of food on food choices and intake. Curr. Obes. Rep. 2016, 5, 65-71. [CrossRef] [PubMed]

44. Hajra, N.G. Organic tea: Global market and forecast sales. J. Tea Sci. Res. 2017, 7, 58-68. [CrossRef]

45. Anabtawi, O.; Swift, J.A.; Hemmings, S.; Gertson, L.; Raaff, C. Perceived healthiness of food items and the traffic light front of pack nutrition labelling: Choice-based conjoint analysis and cross-sectional survey. J. Hum. Nutr. Diet. 2020, 33, 487-495. [CrossRef]

46. Branscombe, N.R.; Baron, R.A. Social Psychology; Pearson: New York, NY, USA, 2017.

47. Solomon, M.R. Consumer Behavior: Buying, Having and Being; Pearson: New York, NY, USA, 2018.

48. Rosenberg, M.J.; Hovland, C.I. Attitude organization and change: An analysis of consistency among attitude components. In Cognitive, Affective, and Behavioral Components of Attitude; Rosenberg, M.J., Hovland, C.I., McGuire, W.J., Abelson, R.P., Brehm, J.W., Eds.; Yale University Press: New Haven, CT, USA, 1960; pp. 1-14. 
49. Anselmsson, J.; Burt, S.; Tunca, B. An integrated retailer image and brand equity framework: Re-examining, extending, and restructuring retailer brand equity. J. Retail. Consum. Serv. 2017, 38, 194-203. [CrossRef]

50. Yoon, S.; Park, J.E. Tests of in-store experience and socially embedded measures as predictors of retail store loyalty. J. Retail. Consum. Serv. 2018, 45, 111-119. [CrossRef]

51. Hwang, J.; Chung, J.E. What drives consumers to certain retailers for organic food purchase: The role of fit for consumers' retail store preference. J. Retail. Consum. Serv. 2019, 47, 293-306. [CrossRef]

52. Prakash, G.; Singh, P.K.; Yadav, R. Application of consumer style inventory (CSI) to predict young Indian consumer's intention to purchase organic food products. Food Qual. Prefer. 2018, 68, 90-97. [CrossRef]

53. Kline, R.B. Principles and Practice of Structural Equation Modeling; The Guilford Press: New York, NY, USA, 2011.

54. Hair, J.F.; Black, W.C.; Babin, B.J.; Anderson, R.E. Multivariate Data Analysis: A Global Perspective; Pearson: Upper Saddle River, NJ, USA, 2010.

55. Podsakoff, P.M.; MacKenzie, S.B.; Lee, J.Y.; Podsakoff, N.P. Common method biases in behavioral research: A critical review of the literature and recommended remedies. J. Appl. Psychol. 2003, 88, 879-903. [CrossRef] [PubMed]

56. Preacher, K.J.; Rucker, D.D.; Hayes, A.F. Addressing moderated mediation hypotheses: Theory, methods, and prescriptions. Multivar. Behav. Res. 2007, 42, 185-227. [CrossRef] [PubMed]

57. Nguyen, H.V.; Nguyen, N.; Nguyen, B.K.; Lobo, A.; Vu, P.A. Organic food purchases in an emerging market: The influence of consumers' personal factors and green marketing practices of food stores. Int. J. Envirion. Res. Public Health 2019, 16, 1037. [CrossRef] [PubMed]

58. Yin, S.; Chen, M.; Chen, Y.; Xu, Y.; Zou, Z.; Wang, Y. Consumer trust in organic milk of different brands: The role of Chinese organic label. Br. Food J. 2016, 118, 1769-1782. [CrossRef]

59. Jonas, A.; Roosen, J. Demand for milk labels in Germany: Organic milk, conventional brands, and retail labels. Agribus. Int. J. 2008, 24, 192-206. [CrossRef]

60. Ismael, D.; Ploeger, A. The potential influence of organic food consumption and intention-behavior gap on consumers' subjective wellbeing. Foods 2020, 9, 650. [CrossRef]

61. Soroka, A.; Wojciechowska-Solis, J. Consumer motivation to buy organic food depends on lifestyle. Foods 2019, 8, 581. [CrossRef]

62. Hughner, R.S.; McDonagh, P.; Prothero, A.; Shultz, C.J.; Stanton, J. Who are organic food consumers? A compilation and review of why people purchase organic food. J. Consum. Behav. Int. Res. Rev. 2007, 6, 94-110. [CrossRef]

(C) 2020 by the authors. Licensee MDPI, Basel, Switzerland. This article is an open access article distributed under the terms and conditions of the Creative Commons Attribution (CC BY) license (http://creativecommons.org/licenses/by/4.0/). 